\title{
O adoecimento na perspectiva de crianças escolares atendidas em uma unidade de pronto atendimento
}

\author{
IIIness on the perspective of school children seen at an emergency care unit
}

La enfermedad desde la perspectiva de los escolares atendidos en urgencias

\author{
Bárbara Luiza Cordeiro da Silva ${ }^{1 *}$, Flávia dos Santos Silva1, Elaine Cristina Rodrigues Gesteira .
}

\section{RESUMO}

Objetivo: Compreender o significado do adoecimento na perspectiva da criança durante a sua permanência em uma unidade de pronto-atendimento. Métodos: Pesquisa exploratória e descritiva com abordagem qualitativa realizada com 17 crianças de seis a doze anos atendidas em uma unidade de pronto-atendimento da região centro-oeste mineira, no período de agosto a dezembro de 2019. Os instrumentos utilizados na coleta foram as entrevistas semiestruturadas ancoradas na aplicação do brinquedo terapêutico dramático. Resultados: As crianças atribuíram significados a condição de adoecimento, expressaram tristeza, sofrimento, dor e apreensão diante dos procedimentos; a experiência por meio do brinquedo terapêutico induziu a catarse, destacando-se o simbolismo na relação de estar doente e o ambiente pediátrico, como algo ameaçador. Conclusão: Os resultados trazem contribuição à compreensão de como as crianças veem a doença, internação e os procedimentos invasivos, destacando o medo relacionado ao ambiente e aos profissionais, reforçando a importância da escuta ampliada e multiprofissional, além do uso do brinquedo terapêutico na prática profissional do enfermeiro.

Palavras-chave: Criança hospitalizada, Doença, Desenvolvimento infantil, Jogos e brinquedos.

\begin{abstract}
Objective: To understand the meaning of illness from the child's perspective during his stay in an emergency care unit. Methods: Exploratory and descriptive research with a qualitative approach done to 17 children aged six to twelve years attended at an emergency care unit in the Midwest region of Minas Gerais, from August to December 2019. The instruments used to collect were semi-structured interviews anchored in the application of the dramatic therapeutic toy. Results: Children attributed meanings to the illness condition, expressed sadness, suffering, pain and apprehension against the procedures; the experience through the therapeutic toy induced catharsis, highlighting the symbolism in relation to being sick and the pediatric environment, as something threatening. Conclusion: The results contribute to the understanding of how children see the disease, hospitalization and invasive procedures, highlighting the fear related to the environment and professionals, reinforcing the importance of extended and multiprofessional listening, besides the use of therapeutic toys in the nurse's professional practice.
\end{abstract}

Keywords: Child hospitalized, Disease, Child development, Play and playthings.

\section{RESUMEN}

Objetivo: Comprender el significado de la enfermedad desde la perspectiva del niño durante su estancia en una Unidad de Cuidados de Emergencia. Métodos: Investigación exploratoria y descriptiva con enfoque cualitativo realizada con 17 niños de seis a doce años atendidos en una Unidad de Cuidados de Emergencia en la región Medio Oeste de Minas Gerais, de agosto a diciembre de 2019. Los instrumentos utilizados en la colecta fueron entrevistas semiestructuradas. anclados en la aplicación del dramático juguete terapéutico. Resultados: Los niños atribuyeron significados a la condición de enfermedad, expresaron tristeza, sufrimiento, dolor y aprensión ante los procedimientos; la experiencia a través del juguete terapéutico indujo la catarsis, destacando el simbolismo en la relación del enfermo y el entorno pediátrico, como algo

1 Universidade Federal de São João del-Rei (UFSJ), Divinópolis - MG. *E-mail: elaine_gesteira@ufsj.edu.br 
amenazador. Conclusión: Los resultados contribuyen a la comprensión de cómo los niños ven la enfermedad, la hospitalización y los procedimientos invasivos, destacando el miedo relacionado con el entorno y los profesionales, reforzando la importancia de la escucha extendida y multiprofesional, además del uso de juguetes terapéuticos en la práctica profesional del enfermero.

Palabra clave: Niño hospitalizado, Enfermedad, Desarrollo infantil, Juego e implementos de juego.

\section{INTRODUÇÃO}

A doença na infância é um acontecimento abrupto, que dependendo do grau de gravidade, pode gerar sequelas físicas e psíquicas impactantes para o desenvolvimento infantil devido às limitações impostas pela própria doença e a condição de permanência em unidades de pediatria (LEITE AC, et al.,2019; SIMÕES K, et al., 2020).

Trata-se de um contexto perturbador na vida de uma criança, onde ela passa por mudanças bruscas de sua rotina diária como o afastamento de seu lar, com restrições alimentares, limitações no ato de brincar, perda de sua autonomia, afastamento dos familiares, além de ser submetida a procedimentos dolorosos e invasivos, permanecendo em um ambiente com profissionais que estão fora do seu ciclo de convivência (FARIAS D, et al., 2017).

A procura por unidades de pronto-atendimento (UPA) e a necessidade de internação da criança, mesmo que seja por um curto período para observação, se constitui um grande desafio para ela e sua família, pois o sofrimento, a angústia e o medo do desconhecido dificultam a compreensão da situação. Ademais, a criança possui um número limitado de mecanismos de enfrentamento para resolver os fatores estressores, sendo suas reações a essas crises influenciadas pela idade, experiência prévia com a doença, separação ou hospitalização, habilidades de confronto inatas e adquiridas, gravidade do diagnóstico e o sistema de suporte ofertado (FARIAS D, et al., 2017).

Nesse sentido, o ambiente pediátrico deve contribuir para o desenvolvimento da criança, não bastando curar, mas sim auxiliá-la junto à sua família no enfrentamento do processo de saúde e doença. Sendo assim, torna-se imprescindível que a unidade pediátrica tenha profissionais preparados, os quais favoreçam e estimulem o completo bem-estar da criança e de sua família. Nessa perspectiva, destaca-se o papel do enfermeiro no estabelecimento do vínculo e nas ações para um cuidado lúdico e humanizado.

Cabe destacar que esse cuidado pode ser facilitado com a técnica do Brinquedo Terapêutico, uma intervenção pediátrica baseada na brincadeira organizada, cujo objetivo é aliviar tensões e ansiedades causadas pela vivência de situações incomuns às crianças (SIMIONE G, et al., 2017).

Frente ao exposto, percebe-se o avanço de estudos relacionados a criança hospitalizada (RIBEIRO C, et al., 2012; SILVA T, et al., 2017; SANTOS V, et al., 2020), bem como, o impacto das atividades lúdicas como intervenção, porém notou-se uma escassez de pesquisas que abordassem os sentimentos das crianças sobre a sua própria doença em ambientes como as unidades de pronto-atendimento, utilizando o brinquedo terapêutico como instrumento de coleta em pesquisa.

Desse modo, o objetivo dessa investigação foi compreender o significado do adoecimento na perspectiva da criança durante a sua permanência em uma UPA, pois acredita-se que essa pesquisa possa contribuir para o planejamento de um cuidado de enfermagem que garanta a centralidade na criança e sua família, com o foco na sua integridade biopsicossocial, considerando o infante como um ser em crescimento e desenvolvimento, e que deve ter a sua autonomia respeitada diante da doença e dos procedimentos.

\section{MÉTODOS}

Trata-se de um estudo exploratório e descritivo com abordagem qualitativa, tendo como arcabouço teórico o interacionismo simbólico, uma teoria que tem como base a interpretação de significados de produtos sociais, determinadas por seu processo interativo e caracterizado pela utilização de símbolos para um determinado contexto social (PATIAS ND, et al., 2019; BUENO T, et al., 2017). 
O estudo foi realizado no setor de pediatria de uma Unidade de Pronto Atendimento (UPA) do Sistema Único de Saúde (SUS), situado na região Centro Oeste do estado de Minas Gerais. As crianças atendidas permanecem na unidade, onde são realizados exames e cuidados de baixa e média complexidade, sendo a sua permanência variável de acordo com o quadro clínico, podendo estender-se por várias semanas.

Participaram do estudo 17 crianças com idade de seis a doze anos, de ambos os sexos, de condições diversas, sem previsão de alta e que estavam em condições de verbalizar e interagir com os brinquedos para as entrevistas. O número de participantes foi delimitado a partir da técnica de "saturação dos dados", definida como a suspensão da inclusão de novos participantes a partir do momento em que os dados passam a certo grau de repetição (PATIAS ND, et al., 2019).

Foram excluídas crianças que apresentavam dificuldades de verbalização e patologias caracterizadas por atraso de desenvolvimento neuropsicomotor e cognitivo. Após assentimento verbal da criança em participar do estudo, os responsáveis legais concordaram assinar o Termo de Consentimento Livre e Esclarecido.

A coleta ocorreu nos meses de agosto a dezembro de 2019, sendo utilizados os instrumentos: entrevistas semiestruturadas intermediadas pela técnica do brinquedo terapêutico dramático (BTD), com bonecos e materiais de brinquedo que simbolizavam a equipe de saúde e os procedimentos. Vale ressaltar que as pesquisadoras foram capacitadas e acompanhadas pela orientadora do estudo para a sessão do brinquedo terapêutico, seguindo as etapas recomendadas pelas autoras Ribeiro CA, et al. (2012), convidando a criança para brincar; explicando a presença do acompanhante; apresentando os brinquedos disponíveis; orientação do tempo para brincar e a devolução dos brinquedos; brincadeira não direcionada deixando a criança brincar, perguntar e responder livremente. Para isso, a coleta foi executada em dois momentos:

Primeiro momento: Realizou-se o convite a criança e ao acompanhante para participarem do estudo. Neste primeiro contato, em caso de aceite foram coletados com o familiar dados sobre a idade da criança, diagnóstico médico e tempo de permanência na UPA. Segundo momento: Foi conduzida a entrevista com a criança por meio de questões norteadoras sobre doença, internação e percepção frente aos procedimentos realizados na UPA, intermediada com a sessão de brinquedo terapêutico, utilizando-se um roteiro estruturado.

As etapas das entrevistas ocorreram a partir do aceite da criança e de seu acompanhante, em seguida convidava-se a criança para brincar, dispondo os brinquedos (bonecos que representavam a equipe de saúde, brinquedos hospitalares como estetoscópio, seringa, termômetro, entre outros). Nesse momento, enquanto a criança se familiarizava com os brinquedos, se iniciava com a pergunta sobre como era estar doente e o que ela tinha mais medo, conforme ela respondia se solicitava que ela mostrasse no boneco qual o procedimento que ela tinha sido submetida na UPA, e aquele que lhe causava medo e dor. Ao mesmo tempo em que ela brincava, e manifestava a catarse durante a brincadeira, os pesquisadores registravam por meio de gravações e fotos, os dados coletados, os quais foram transcritos para posterior análise.

$O$ registro fotográfico foi realizado com foco na brincadeira, mostrando a manipulação delas com o brinquedo durante a sessão, a fim de não a identificar e preservar a sua imagem. A fotografia caracterizou o elemento simbólico de como a criança vivencia a doença e o estar na UPA, sendo uma técnica que auxiliou na identificação da simbologia, a qual foi necessária de acordo com o referencial teórico escolhido nesse estudo.

Os dados foram analisados de acordo com a análise de conteúdo proposta por Bardin $L$ (2014), em torno de três polos: a pré-análise; a exploração do material; e o tratamento dos resultados, com a inferência e a interpretação dos achados. A análise de conteúdo é uma técnica que exige muita dedicação, paciência e tempo do pesquisador, o qual necessita compreender o sentido dado pelos depoentes para definir as categorias temáticas.

O presente estudo atendeu a Resolução 466 de 2012, respeitando-se os referenciais da bioética: a autonomia, não maleficência, beneficência, justiça e equidade, sendo submetido no Comitê de Ética e Pesquisa da Universidade Federal de São João del Rei-UFSJ e autorizada pelo parecer: 3.383.805.

Após as transcrições, os áudios foram descartados a fim de manter o sigilo e a confidencialidade. Para preservar o anonimato, as crianças foram identificadas pela letra $\mathrm{C}$, seguidos de uma enumeração. 


\section{RESULTADOS E DISCUSSÃO}

Participaram da pesquisa 17 crianças, nove meninas e oito meninos, com diagnósticos clínicos diversos e tempo de internação variável em horas e dias (Quadro 1).

Quadro 1 - Principais características dos participantes do estudo. Divinópolis-MG 2020.

\begin{tabular}{|l|c|c|l|c|}
\hline \multicolumn{1}{|c|}{ Participante } & Sexo & Idade & \multicolumn{1}{|c|}{ Diagnóstico médico } & $\begin{array}{c}\text { Tempo de internação } \\
\text { e/ou observação na } \\
\text { unidade }\end{array}$ \\
\hline Sininho & F & 11 & Intoxicação alimentar. & 6 horas \\
\hline Homem de ferro & M & 6 & Dor abdominal a esclarecer. & 3 dias \\
\hline Cinderela & F & 12 & Amigdalite bacteriana. & 3 horas \\
\hline Flash & M & 11 & Gripe. & 2 dias \\
\hline Mulher maravilha & F & 7 & Bronquite. & 8 horas \\
\hline Lindinha & F & 9 & Gripe. & d dia \\
\hline Ariel & F & 7 & Febre a esclarecer & 2 horas \\
\hline Margarida & F & 9 & Gripe. & 3 dias \\
\hline Moranguinho & F & 6 & Pneumonia. & 3 horas \\
\hline Ben 10 & M & 8 & Hipoglicemia. & 5 dias \\
\hline Batman & M & 6 & Alérgico a esclarecer & 4 horas \\
\hline Mickey & M & 8 & Síndrome de Kawasaki. & 5 horas \\
\hline Minnie & F & 7 & Virose. & 4 dias \\
\hline Wood & M & 11 & Queda. & 5 horas \\
\hline Super homem & M & 8 & $\begin{array}{l}\text { Fratura supracondiliana do cotovelo após } \\
\text { queda. }\end{array}$ & 5 horas e 40 minutos \\
\hline Florzinha & F & 11 & Virose. & \\
\hline Homem aranha & M & 7 & Pneumonia. & \\
\hline Fonte: Siva BLC & & & \\
\hline
\end{tabular}

Fonte: Silva BLC, et al., 2020.

Foram realizadas 17 entrevistas com as crianças, sendo que todos os participantes conseguiram responder as questões e interagir com o brinquedo, não houve nenhuma criança que não tenha aceitado a participar. Desse modo, os dados foram extraídos, a partir dos significados de suas narrativas, e os simbolismos por meio do BTD, o que contribuiu para a compreensão do fenômeno e a identificação de três categorias temáticas: "Percepção da criança em relação a doença e a internação"; "A importância do cuidado por meio do brinquedo terapêutico" e a "Percepção da criança diante dos procedimentos dolorosos".

\section{Percepção da criança em relação à doença e a internação}

Entende-se que a permanência de uma criança em um ambiente pediátrico gera ansiedade, estresse e temor. A vivência da doença e a internação por horas ou dias, expõe a criança ao sofrimento, perda de sua autonomia e limitação ao leito, o que para ela é assustador.

Nesse contexto, ela se encontra em um ambiente hostil, com profissionais usando suas roupas brancas e que realizam procedimentos, muitas vezes dolorosos. Estar doente impõe a ruptura de suas atividades como brincar, estudar, estar com a família, além disso, há a expectativa em torno do diagnóstico e de como será o tratamento (CARDOSO N, et al., 2017).

Quando as crianças foram entrevistadas sobre como se sentiam diante da doença e internação na UPA, as falas revelaram diferentes sentimentos e significados de ordem física, emocional e social. 
"[...] ficar doente é estranho, fiquei nervoso, estranho, sei lá não sei explicar direito [...] não gosto de ter que ficar aqui olhando essa cortina verde" (C1).

"Eu estou com dor na barriga, [...] vomitando [...] não gosto de ficar doente, não dá para fazer nada" (C2).

"Quando estou doente me sinto triste, é ruim" (C3).

"É porque eu estou com uma doença que chama Síndrome de Kawasaki" (C4).

"Me sinto mais ou menos. Não consigo fazer quase nada, e fico triste porque é muito chato" (C5).

"É o dia todo vendo essas cortinas verdes [...]" (C4).

A experiência da doença traz melancolia e tristeza nas crianças, as falas apontam para as limitações do ambiente e de sua condição, impelidas a aceitar os procedimentos realizados pelos profissionais. Assim, o modo como a criança percebe a sua própria doença está ligado ao processo de restabelecimento de sua saúde, o qual resultará em sentimentos, que devem ser valorizados e considerados durante a prestação de cuidados pela equipe (COSTA S e MORAIS A, 2017; ALVES L, et al.,2019).

"Ficar deitado, só fico deitado, não tem nada para fazer [...]" (C6).

"[Falta] de poder ir jogar bola, brincar e ficar na minha casa, aqui é ruim" (C7).

"Não gosto, não gosto de médico e nem de remédio, é muito ruim ficar aqui, queria ficar em casa" (C8).

"Eu fico com medo de quando chego aqui e vejo um monte de gente doente, deitado no corredor, sangue, credo!" (C3).

"Tenho medo do médico falar que eu tenho uma coisa mais grave" (C9).

Os participantes ressaltam a vontade de voltar para a rotina que tinham antes do adoecimento, algumas limitações interferem no cotidiano com os amigos, familiares e até no ambiente onde eles se encontram, como revelam as falas a seguir:

“É ruim, porque não posso brincar de carrinho" (C4).

"É ruim, porque eu fico muito triste, não fico muito feliz, não consigo fazer nada" (C10).

A internação para a criança é diferente de tudo que ela está acostumada, passa por procedimentos dolorosos, é privada das atividades rotineiras, encontra-se em um ambiente diferente, além disso, é imposta ao convívio com pessoas que não se encontram em seu cotidiano (CARDOSO N, et al., 2017).

Nesse sentido, embora a criança seja encorajada a vivenciar esse ambiente hostil, ela pode mostrar-se chorosa e deprimida, renunciando colaborar com as práticas assistenciais. Desse modo, o trabalho dos profissionais de saúde precisa utilizar o lúdico em suas ações, a fim de favorecer o enfrentamento da doença pela criança e sua família (SANTOS P, et al., 2016; OLIVEIRA 0, et al., 2020).

\section{A importância do cuidado por meio do brinquedo terapêutico}

As percepções narradas e simbolizadas pelas crianças evidenciam que estar doente impõe o afastamento de seus lares, família e amigos. O espaço da escola vivenciado diariamente é rompido, e os procedimentos são vistos e vividos com temor, conforme os relatos abaixo:

"Não consigo fazer quase nada, fico triste porque é chato ficar aqui e não brincar e ir para a escola com meus amigos, hoje tinha educação física" (C11).

"Eu me sinto ruim, porque não tem nada para fazer aqui, só tenho que ficar sentado sem fazer nada, é ruim" (C6).

"[...]Só não gosto muito do soro, porque não pode mexer muito o braço se não [vou] perder a veia" (C12). 
Como uma solução para minimizar esse contexto, uma viável prática a ser trabalhada é o uso do brinquedo durante as intervenções, representados na Figura 1 e 2 sendo que através dele é possível ilustrar para a criança o procedimento a ser realizado, e ainda, pode ser utilizado como uma maneira da mesma descarregar sentimentos, medos e anseios vivenciados nesse momento delicado (BERTÉ C, et al., 2017; SANTOS V, et al., 2020).

Figura 1 - Aplicação do BTD, Divinópolis-MG, 2019.

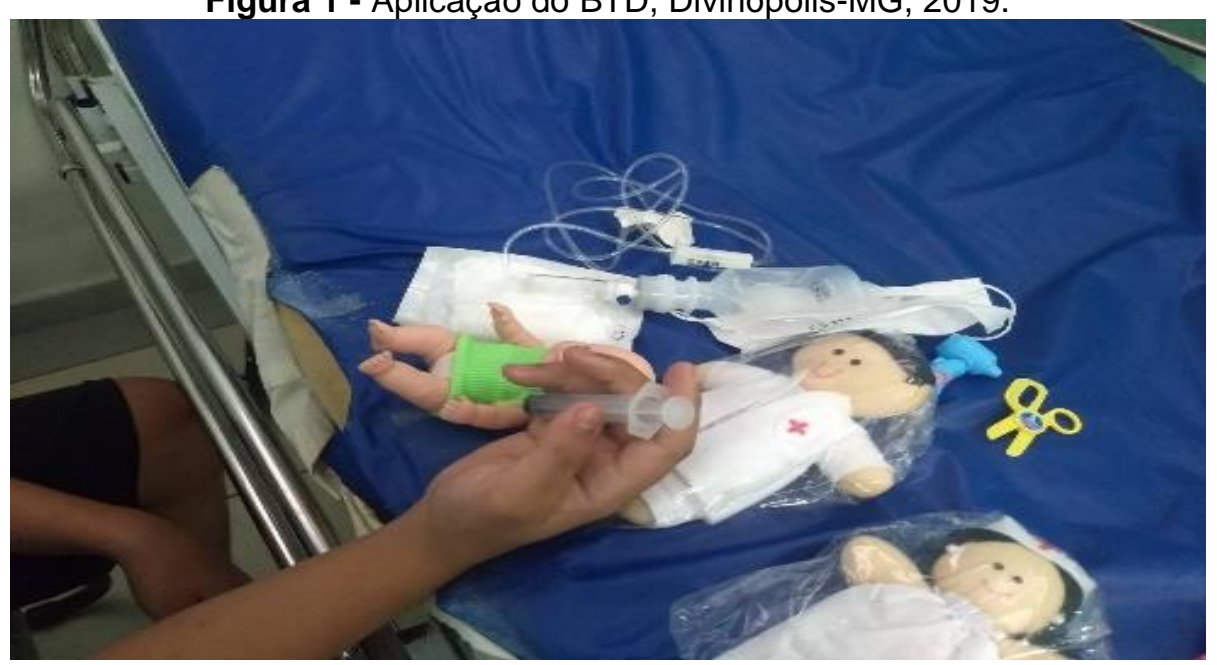

Fonte: Silva BLC, et.al.,2020.

Figura 2 - Aplicação do BTD, Divinópolis-MG, 2019.

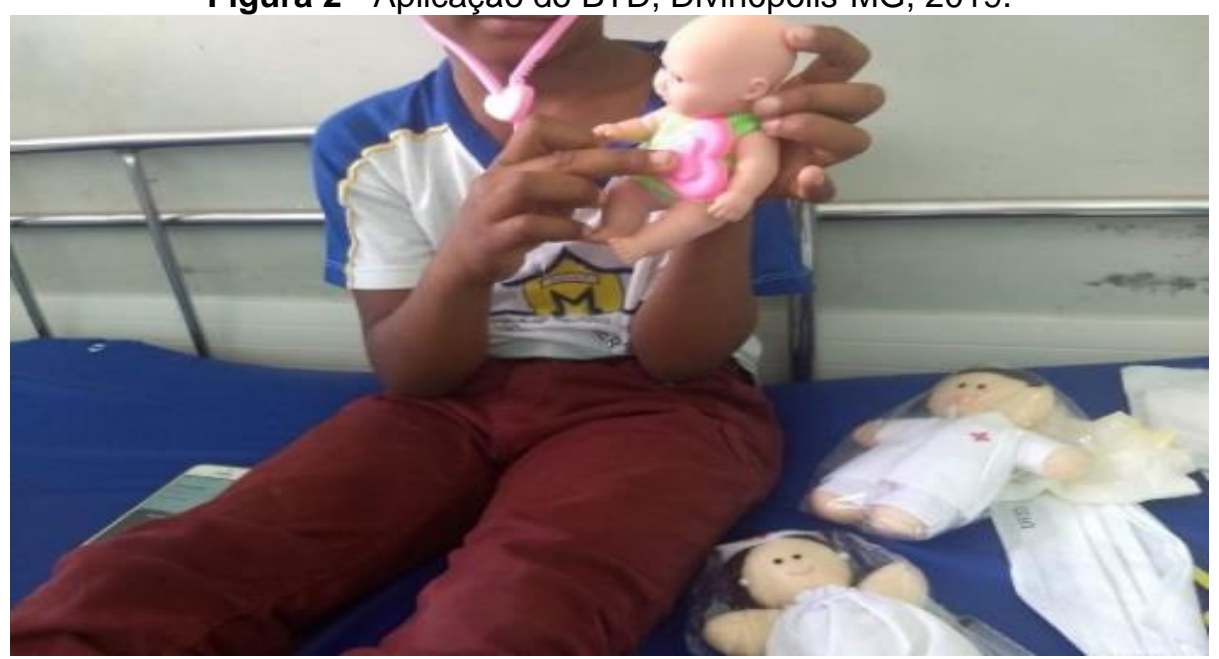

Fonte: Silva BLC, et al., 2020.

O BTD além de auxiliar na coleta de dados, é uma forma efetiva de intervenção para o enfermeiro durante a sua assistência. Nesse contexto, as falas seguintes revelam como as crianças descrevem os procedimentos vividos:

"Depois que eu passei pelo médico eu vim para cá, o médico colocou um negócio para ouvi o meu coração e nas minhas costas, ah e também um palito na minha garganta para olhar ela [...] injeção, ela pegou a cordinha e amarrou no meu braço, passou um algodão e colocou a agulha, aí depois colocou o soro e ficou pingando lá devagarinho. Aí eu melhorei" (C13).

"Tenho medo disso (estetoscópio) coloca nas costas e na barriga (faz o procedimento nas costas do boneco sem colocar o estetoscópio na orelha e com receio de tocá-lo)" (C14). 
O brincar pode ser usado como uma técnica para criar vínculo entre os profissionais da enfermagem e a criança, por meio das brincadeiras o ambiente pediátrico e os procedimentos se tornam mais suportáveis, assim facilitam os mesmos a esquecerem um pouco a realidade em que estão vivenciando e dá a oportunidade de se descontraírem, além de expressar seus sentimentos e compartilhar suas experiências, contribuindo para um melhor atendimento em diversas áreas (SILVA T, et al., 2017). Os sentimentos apreensivos durante os procedimentos são ressaltados por eles conforme relatos a seguir:

"Quando coloca o soro dói, mais e depois que tira para de doer, fica um buraco na minha mão" (C15).

"Ah é ruim também, porque não tem nada para fazer, eu fico aqui atoa, não tem nada para fazer, nem internet, nem televisão" (C12).

"Só não gosto de ficar aqui sem fazer nada, o celular da minha irmã acabou a bateria e nem dá para fazer nada" (C16).

Dessa maneira o uso do brinquedo promove o bem-estar físico e alívio emocional das tensões causadas pela doença (SILVA T, et al., 2017). Ele possibilita expor sentimentos, assim como experiências que não são verbalizadas, aliviando as tensões e expondo os medos implicados à situação estressante. A forma como é aplicado consiste em permitir à criança simular situações que estão sendo vivenciadas durante a internação, podendo assumir o papel de qualquer membro da equipe de cuidado ou de algum familiar. Ao encenar esses papéis durante a brincadeira, pode-se encontrar soluções para os problemas enfrentados (SOSSELA C e SAGER F, 2018; SILVA T, et al., 2017; BARROSO MC, et al., 2020).

Nesse estudo, o BTD favoreceu a coleta de dados, visto que de acordo com as entrevistas, elas se sentiram à vontade para mostrarem nos bonecos os procedimentos que eram realizados com elas, e assim mostravam e verbalizavam seus sentimentos, como dor, temor e ociosidade no ambiente. É válido ressaltar que os pais se envolveram na brincadeira, e isso proporcionou um momento de grande descontração.

Para Costa S (2017) são importantes a presença e a participação dos pais e/ou cuidadores durante todo o processo de doença e internação; ao se fazerem presentes acompanhando seus filhos, isso promove segurança e tranquilidade, minimizando a ansiedade do núcleo familiar.

\section{Percepção da criança diante dos procedimentos dolorosos}

$\mathrm{Na}$ percepção das crianças os procedimentos e intervenções pelos quais passaram na UPA foram descritos como um momento de medo e dor, o que pode ser evidenciado diante das falas:

"Eu sinto dor quando ela me dá injeção [...]" (C3).

"Só fiquei com medo de ficar com isso aqui (mostrou o soro). E fiquei com medo também de ter que operar" (C6).

"Eu me sinto com medo, com muito medo" (C10).

"Ahh é muito ruim, a gente fica nervoso, preocupado, é muito ruim mesmo" (C1).

"[Medo] da injeção. Dói muito, eu não gosto não [...] Ah não é bom não, é ruim, porque não tem nada para fazer, eu fico triste e quando estou com dor aí eu fico querendo chorar" (C13).

"Tenho medo da agulha (disse esquivando-se e falando) não, não, não!" (C8).

A experiência da internação na infância é quase sempre traumática, podendo desencadear o surgimento de diversos sentimentos como angústia, ansiedade e medo diante da situação desconhecida. A condição torna-se ameaçadora, somando-se os procedimentos invasivos, as quais precisam ser submetidas para 0 tratamento e reabilitação (FARIAS D, et al., 2017).

"Tenho medo da agulha, não gosto, a mulher veio aqui e me tirou sangue e é ruim" (C11).

"Tenho medo do remédio, antes dele eu choro e dói, depois eu melhoro" (C16).

"O que eu mais fiquei com medo foi da injeção, na hora eu chorei por que doeu" (C15). 
Os procedimentos invasivos que envolvem agulha são os mais temidos pelas crianças, gerando sentimentos de dor e ansiedade, onde a criança geralmente reage com desconforto emocional e resistência física (FURTADO K, et al., 2020).

Segundo Alves L (2019) e Paula G, et al. (2019) é importante que os profissionais da área de saúde criem mecanismos para uma assistência efetiva à criança, isso inclui as práticas de atividades lúdicas e humanizadas que possam favorecer a comunicação e a distração em ambientes que para elas são hostis e amedrontadores, como na UPA, em que os procedimentos são realizados de forma ágil e com o mínimo de ludicidade.

Desse modo, ressalta-se a necessidade do enfermeiro em preparar a criança e sua família antes da realização dos procedimentos invasivos, a fim de minimizar o medo do desconhecido e promover a sua colaboração para o enfrentamento da doença (BARROSO M, et al., 2020 e OLIVEIRA OP, et al., 2020).

\section{CONCLUSÃO}

Os resultados trazem contribuição à compreensão de como as crianças veem a doença, internação e os procedimentos invasivos, destacando o medo relacionado ao ambiente e aos profissionais, reforçando a importância da escuta ampliada e multiprofissional, além do uso do brinquedo terapêutico na prática profissional do enfermeiro. Sugerem-se novos estudos sobre a percepção das crianças em unidades primárias e secundárias no processo de saúde e doença, além de incentivo a prática do BTD como instrumento de coleta e intervenção.

\section{REFERÊNCIAS}

1. ALVES LRB, et al. A criança hospitalizada e a ludicidade. Rev Min Enferm, 2019;23:1-9

2. BARDIN, L. ANÁLISE DE CONTEÚDO. Lisboa I Portugal, 2014. Edições 70. 229 p.

3. BARROSO M, et al. Percepção das crianças acerca da punção venosa por meio do brinquedo terapêutico. Acta Paul Enferm, 2020;33:1-8

4. BERTÉ C, et al. Brinquedo terapêutico no contexto da emergência pediátrica. Revista Baiana de Enfermagem, 2017;31(3):1-10

5. BUENO T, et al. Interacionismo Simbólico como ferramenta teórica e metodológica para o estudo no ciberespaço. Primera Revista Electrónica Enlberoamérica Especializada EnComunicación, 2017; 21(1): 456-475.

6. CARDOSO $\mathrm{N}$, et al. Vivenciando o processo cirúrgico: percepção e sentimentos da criança. Rev Baiana Enferm,2017;31(3):1-10.

7. LEITE ACAB, et al. Crianças em seguimento ambulatorial: perspectivas do atendimento evidenciadas por entrevista com fantoche. Rev Bras Enferm, 2019;40:1-10

8. COSTA T, MORAIS A. A hospitalização infantil: vivência de crianças a partir de representações gráficas. Recife: Rev Enferm UFPE OnLine, 2017;11(1): 358-367

9. FARIAS D et al. A hospitalização na perspectiva da criança: Uma revisão integrativa. Recife: Rev Enferm UFPE OnLine, 2017;11(2): 703-711

10. FURTADO K, et al. O Uso do Jogo Digital "Hospital Mirim" como Estratégia de Enfrentamento à Procedimento Invasivo. Estudos e Pesquisas em Psicologia; 2020;20(1): 251267.

11. OLIVEIRA OP, et al. A percepção de crianças escolares acerca da hospitalização: estudo com dados qualitativos. Revista Eletrônica Acervo Saúde, 2020; (50): e3409.

12. PAULA G, et al. Estratégias lúdicas no cuidado de enfermagem à criança hospitalizada / Play strategies in nursing care for the hospitalized child. Recife:Rev. enferm. UFPE Online, 2019; 13 91):1-11

13. PATIAS ND, HOHENDORFF JV. Critérios de qualidade para pesquisa qualitativa. Psicol Est,2019;24:e43536

14. RIBEIRO C, et al.Utilizing therapeutic play in care of the child. São Paulo: Atheneu, 2012. p. 127-34.

15. SANTOS V, et al. Compreendendo a sessão do brinquedo terapêutico: contribuição para a enfermagem pediátrica. Rev. Bras. Enferm. Brasília, 2020;73(4): e20180812.

16. SANTOS $P$, et al. Os cuidados de enfermagem na percepção da criança hospitalizada. Rev Bras Enferm, 2016; 69(4): 646-653.

17. SILVA T, et al. Influência do Brinquedo Terapêutico na ansiedade de crianças escolares hospitalizadas: Ensaio clínico. Rev Bras de Enferm. 2017; 70(6):1244-1249

18. SIMÕES K, et al. Vozes à infância silenciada: impactos da hospitalização e hemodiálise à escolarização de crianças com doença renal crônica. Revista Educação Especial,2020;33(1):345-363

19. SIMIONI G, et al. A influência do lúdico no processo de hospitalização infantil: a visão do palhaço. Archives of health investigation, 2017; 6(1):5-9.

20. SOSSELA R, SAGER F. A criança e o brinquedo no contexto hospitalar. Rev. SBPH. Rio de Janeiro, 2017; $20(1)$ : 1731. 